\title{
Leachate Electrical Conductivity and Growth of Potted Geranium with Leaching Fractions of 0 to 0.4
}

\author{
Catherine S.M. Ku ${ }^{1}$ and David R. Hershey ${ }^{2}$ \\ Department of Horticulture, University of Maryland, College Park, MD 20742-5611
}

Additional index words. groundwater, fertigation, irrigation, $\mathrm{pH}$, soluble salts, salinity, Pelargonium $\times$ hortorum

\begin{abstract}
Geraniums (Pelargonium $\times$ hortorum L.H. Bailey 'Yours Truly') were grown in a glasshouse from 15 Mar. to 9 May as single pinched plants in a growing medium with a bulk volume of 1.3 liters per $15 \mathrm{~cm}$ diameter standard plastic pot. Plants received constant fertigation with $\mathrm{N}$ at $300 \mathrm{mg}^{-1 i t e r}{ }^{-1}$ from $20 \mathrm{~N}-4.4 \mathrm{P}-16.6 \mathrm{~K}$ with leaching fractions (LFs) of $\approx 0,0.1,0.2$, and 0.4 . The $L F$ is the volume of solution leached from the container divided by the volume of solution applied to the container. There were 24 irrigations during the study. Plants with LFs of 0.2 and 0.4 had 46\% larger leaf area, $40 \%$ more shoot fresh mass, and $37 \%$ more shoot dry mass than plants with LFs of 0 and 0.1 . By week 5, the leachate electrical conductivity (EC) at $25 \mathrm{C}$ for LFs of $0.1,0.2$, and 0.4 had increased from $\approx 3 \mathrm{dS} \cdot \mathrm{m}^{-1}$ initially to 12,8 , and $4 \mathrm{dS} \cdot \mathrm{m}^{-1}$, respectively. At harvest, the EC of a saturated medium extract $\left(\mathrm{EC}_{\mathrm{e}}\right)$ was $7,4,3$, and $2 \mathrm{dS} \cdot \mathrm{m}^{-1}$ for LFs of $0,0.1,0.2$, and 0.4 , respectively. At harvest, medium EC, with LFs of $0.1,0.2$, and 0.4 was $47 \% 68 \%$, and $60 \%$ less in the lower two-thirds of the pot than in the upper third. With a LF of 0, the medium EC, was 'not lower in the bottom of the pot. With fertigation $N$ at $300 \mathrm{mg}^{-l i t e r}{ }^{-1}$, minimizing the LF substantially reduced growth of container-produced geraniums. In addition to specifying $\mathbf{L F}$, the number of container capacities leached per week, termed the leaching intensity (LI), should be calculated for container leaching studies. In two studies, the LFs may be the same yet the LIs can be very different.
\end{abstract}

Leaching of fertilizers and pesticides from greenhouse container media into the environment is of great concern to floriculture (Biernbaum and Fonteno, 1989). However, little research has examined the minimum amount of leaching required to obtain maximum container crop growth. Ku and Hershey (1991) found that for the salinity-tolerant poinsettia (Euphorbia pulcherrima Willd. ex Klotzsch), growth was the same with a LF of 0 or 0.4 with $\mathrm{N}$ fertigation at $300 \mathrm{mg} \cdot \mathrm{liter}^{-1}$. The LF is defined as the volume of leachate divided by the volume of irrigation solution applied. Yelanich and Biernbaum (1990) obtained acceptable container-grown poinsettia with a LF of 0 to 0.5 and $\mathrm{N}$ fertigation at 100 to $400 \mathrm{mg} \cdot$ liter $^{-1}$, however, shoot fresh mass was significantly less at lower LFs with $\mathrm{N}$ fertigatron at $400 \mathrm{mg} \cdot$ liter $^{-1}$.

Since crops differ in salinity tolerance and growing conditions vary widely, the results from poinsettia do not necessarily apply to other floriculture crops. Poinsettias are grown largely during the fall, when greenhouse evapotranspiration conditions in many areas are typically lower than during spring. The important spring container crop, geranium, is considered substantially less salinity tolerant than poinsettia (Hartmann et al., 1988). Therefore, in this study, we examined the influence of leaching fractions of $0,0.1,0.2$, and 0.4 on spring glasshouse production of container-grown geranium 'Yours Truly'.

\section{Materials and Methods}

Terminal shoot cuttings of 'Yours Truly' geranium were stuck 23 Jan. 1989 in Pro-Mix BX growing medium (Premier Brands, Stamford, Conn.) and placed under a glasshouse intermittent mist system. Pro-Mix BX consists of sphagnum peat, vermiculite, and perlite amended with dolomitic limestone, calcium nitrate, superphosphate, fritted trace elements, and a wetting

Received for publication 3 June 1991. Accepted for publication 28 June 1992. Scientific article no. A6193, contribution no. 8362 of the Maryland Agricultural Experiment Station. The cost of publishing this paper was defrayed in part by the payment of page charges. Under postal regulations, this paper therefore must be hereby marked advertisement solely to indicate this fact.

'Graduate Assistant.

${ }^{2}$ Assistant Professor. To whom reprint requests should be addressed. agent. The rooted cuttings were transplanted into Pro-Mix BX and grown as single pinched plants, one cutting per $15-\mathrm{cm}-$ diameter standard plastic pot (Kord Corp., Lugoff, S.C.) on 15 Mar. Pot volume was 1.8 liters, growing medium bulk volume per pot was 1.3 liters, and medium height was $13 \mathrm{~cm}$. Container capacity determined on five unplanted pots was $65 \%$ of the bulk volume. Plants were spaced $38 \times 38 \mathrm{~cm}$ on raised benches in a glasshouse with the air minimum at $\approx 24 / 18 \mathrm{C}$ (day/night). The irrigation volume required was determined via gravimetric evapotranspiration (ET) measurement. Plants were fertigated 24 times during the 53 day study with $\mathrm{N}$ at $300 \mathrm{mg} \cdot$ liter $^{-1}$ from Peter's Peat-Lite Special (Peters Fertilizers, Fogelsville, Pa.) with $20 \mathrm{~N}-4.4 \mathrm{P}-16.6 \mathrm{~K}-0.15 \mathrm{Mg}-0.1 \mathrm{Fe}-0.56 \mathrm{Mn}-0.2 \mathrm{~B}-0.16 \mathrm{Zn}-$ $0.1 \mathrm{Cu}-0.1 \mathrm{Mo}$. We used $\mathrm{N}$ at $300 \mathrm{mg}$-liter-1 so we could compare this study with that on poinsettia (Ku and Hershey, 1991) that used fertigation with $\mathrm{N}$ at the same rate. The fertilizer contained $60 \%$ nitrate- $\mathrm{N}$ and $40 \%$ ammonium-N. The EC of the irrigation water was $0.3 \mathrm{dS} \cdot \mathrm{m}^{-1}$ at $25 \mathrm{C}$, and the $\mathrm{EC}$ of the fertigation solution was $2.1 \mathrm{dS} \cdot \mathrm{m}^{-1}$. Mean $\mathrm{pH}$ of the irrigation water was 7.5 , and the mean water alkalinity was $64 \mathrm{mg} \cdot \mathrm{liter}^{-1}$ (B. Fisher, personal communication). The medium water content just before fertigation averaged $51 \%$ of the moisture content at container capacity or $33 \%$ of the medium bulk volume. Leaching fraction treatments were $0,0.1,0.2$, or 0.4 . Treatments were replicated five times with one plant per replication and arranged in a completely randomized design.

The planted pots were each set on an empty, overturned 11cm-diameter plastic pot (Kord) that was inside a 2-liter plastic specimen container (VWR Scientific, Philadelphia). At each fertigation, leachate ran into the specimen container. When leaching ended, the leachate volume was determined by pouring the leachate into a graduated cylinder.

The study began 18 Mar. by irrigating pots to saturation. Once leaching had ceased, the initial pot mass after irrigation (M,) was determined. Just before fertigation, the pot mass be-

Abbreviations: EC, electrical conductivity; EC, EC of the applied solution; $\mathrm{EC}_{\mathrm{e}}, \mathrm{EC}$ of a saturated medium extract; ET, evapotranspiration; LF, leaching fraction; LI, leaching intensity; LR, leaching requirement; $M_{a}$, mass of pot after irrigation when at container capacity; $\mathbf{M}_{b}$, mass of pot before irrigation. 

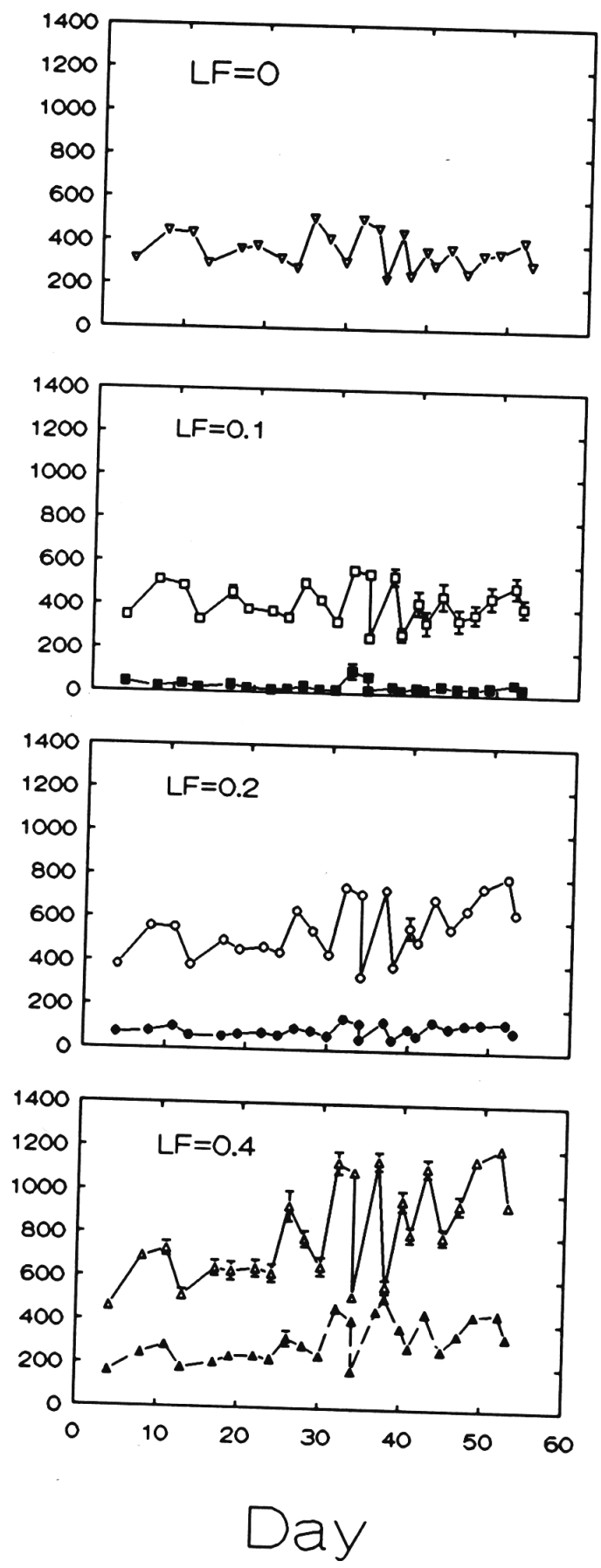

Fig. 1. Fertigation solution volumes applied (open symbols) and leached (closed symbols) for LFs of $0,0.1,0.2$, and 0.4. Each point represents a mean $\pm \mathrm{SE}, \mathrm{n}=5$. If not shown, error bar lies within symbols.

fore irrigation $\left(\mathrm{M}_{\mathrm{b}}\right)$ was determined and subtracted from the previous $\mathrm{M}_{\mathrm{a}}$ to determine ET. The amount of irrigation solution to apply for that fertigation $\left(\mathrm{V}_{\mathrm{a}}\right)$ was calculated as follows $\mathrm{V}_{\mathrm{a}}$ $=[(\mathrm{LF} \times \mathrm{ET}) /(1-\mathrm{LF})]+\mathrm{ET}$, and was applied by means of a graduated cylinder. After drainage stopped, a new $M$ was determined. The volumes applied and leached are shown in Fig. 1. This method generally gave slightly less leaching than required to reach the targeted LF (Ku and Hershey, 1991).

To avoid the decrease in $\mathrm{M}_{\mathrm{a}}$ over time with $0 \mathrm{LF}$, which occurred with poinsettia (Ku and Hershey, 1991), pots were irrigated with extra volumes until leaching just began. Any small volume of leachate obtained was added to the pot in the next irrigation.

Leachate $\mathrm{pH}$ and EC were measured using the methods of $\mathrm{Ku}$ and Hershey (1991). The study ended on 9 May. Plant heights were measured from the top of the pot to the top of the canopy before the stems were cut at the medium surface. Leaf inflorescence, and stem masses were measured to the nearest $0.1 \mathrm{~g}$ on an electronic balance. Leaf area, petiole included was measured with an area meter (LI-COR, Lincoln, Neb.). After oven drying at $40 \mathrm{C}$, dry masses of leaves, stems, and inflorescences were determined.

The growing medium was divided based on height into upper middle, and lower thirds, and a saturated medium sample was prepared with deionized water (Bunt, 1988). A vacuum extract of the saturated medium was then obtained with the apparatus of Hershey (1989). The $\mathrm{pH}$ and EC of the extract were determined and designated EC, and $\mathrm{pH}_{\mathrm{e}}$. Preplant $\mathrm{EC}_{\mathrm{e}}$ was $2.1 \mathrm{dS} \cdot \mathrm{m}^{-1}$ at $25 \mathrm{C}$, and preplant $\mathrm{pH}_{\mathrm{e}}$ was 5.5 .

Graphs and regressions were performed with the program Slidewrite Plus, version 4. Other statistical analyses were done with SAS (SAS Institute, Cary, N.C.).

\section{Results and Discussion}

The overall LFs were all below the target LFs, by $24 \%$ with target $\mathrm{LF}=0.1$ to $8 \%$ with target $\mathrm{LF}=0.4$ (Table 1) as with poinsettia (Ku and Hershey, 1991). However, daily LFs did not decline over time (Fig. 2) unlike the study with poinsettia. Also as in the latter study, ET calculated on a mass basis was only $3.3 \%$ to $6.5 \%$ less than ET calculated on a volume basis (Table 1). The total nutrient solution applied to the geraniums during the 7.5 week study ranged from 8.66 liters at 0 LF to 19.7 liters at $0.4 \mathrm{LF}$ (Table 1). In contrast, poinsettias grown for 10 weeks in the same size pots and the same kind of medium received only 5.6 liters at $0 \mathrm{LF}$ to 10.8 liters at $0.4 \mathrm{LF}$. Thus, although LFs, pot size, growing medium, and fertigation solution were the same for the geraniums in this study and the poinsettias in an earlier study (Ku and Hershey, 1991), the amount of leaching was actually higher in the geraniums. With a $0.4 \mathrm{LF}$ there was $82 \%$ more total leachate in this study with geranium than for the one with poinsettia ( $\mathrm{Ku}$ and Hershey, 1991).

J. Biernbaum (personal communication) suggested that the amount of leaching be related to the container capacity. Using this approach, the amount of leaching was quantified as the mean number of container capacities leached per week and termed the leaching intensity (LI). For geranium, the LI was 0.13 for $0.1 \mathrm{LF}, 0.35$ for $0.2 \mathrm{LF}$, and 1.15 for $0.4 \mathrm{LF}$. For poinsettia (Ku and Hershey, 1991), the LI was 0.058 for 0.1 LF 016 for $0.2 \mathrm{LF}$, and 0.47 for $0.4 \mathrm{LF}$. The difference in $\mathrm{Li}$ between geranium and poinsettia is closely tied to differences in weekly ET, which was $1230 \mathrm{ml}$ at $0.1 \mathrm{LF}, 1510 \mathrm{ml}$ at $02 \mathrm{LF}$ and $1650 \mathrm{ml}$ at $0.4 \mathrm{LF}$ for geranium (Table 1) and $589 \mathrm{ml}$ at 0.1 $\mathrm{LF}, 659 \mathrm{ml}$ at $0.2 \mathrm{LF}$, and $681 \mathrm{ml}$ at $0.4 \mathrm{LF}$ for poinsettia $(\mathrm{Ku}$ and Hershey, 1991). Specifying both-the LI and LF more completely indicates the amount of leaching.

Plant height was similar for LF 0 to 0.4 but leaf area increased with increasing LF (Table 2). The fresh and dry masses of inflorescences at all LFs were similar, but the fresh and dry masses of leaves and stems of plants receiving the two lower LFs were significantly less than those with the two higher LFs (Table 3). The differences between the lower LFs (0 and 0.1) and the two higher LFs ( 0.2 and 0.4$)$ could be related to osmotic stress caused by higher soluble salt accumulation in the medium 
Table 1. Overall volumes of nutrient solution applied and leached, LF and ET, for container-grown geraniums for 7.5 weeks. $^{2}$

\begin{tabular}{lcccccc}
\hline \hline & \multicolumn{7}{c}{ LF } \\
\cline { 2 - 7 } Measurement & 0 & 0.1 & 0.2 & \multicolumn{1}{c}{0.4} \\
\hline Total applied (ml) & $8,660 \pm$ & \pm 247 & $9,990 \pm 682$ & $13,500 \pm 193$ & $19,700 \pm 757$ \\
Total leached $(\mathrm{ml})$ & 0 & $793 \pm 75$ & $2,200 \pm 33$ & $7,290 \pm 252$ \\
Overall LF & 0 & $0.076 \pm 0.003$ & $0.161 \pm 0.002$ & $0.368 \pm 0.002$ \\
ET (g) & $8,100 \pm 222$ & $8,730 \pm 604$ & $10,600 \pm 188$ & $12,000 \pm 486$ \\
ET (ml) & $8,660 \pm 247$ & $9,200 \pm 619$ & $11,300 \pm 173$ & $12,400 \pm 508$ \\
\hline
\end{tabular}

${ }^{\mathrm{z}}$ Data represent mean $\pm \mathrm{sE}, \mathrm{n}=5$.

'Calculated on mass basis using pot mass data.

${ }^{\times}$Calculated on volume basis using volume applied and volume leached data.

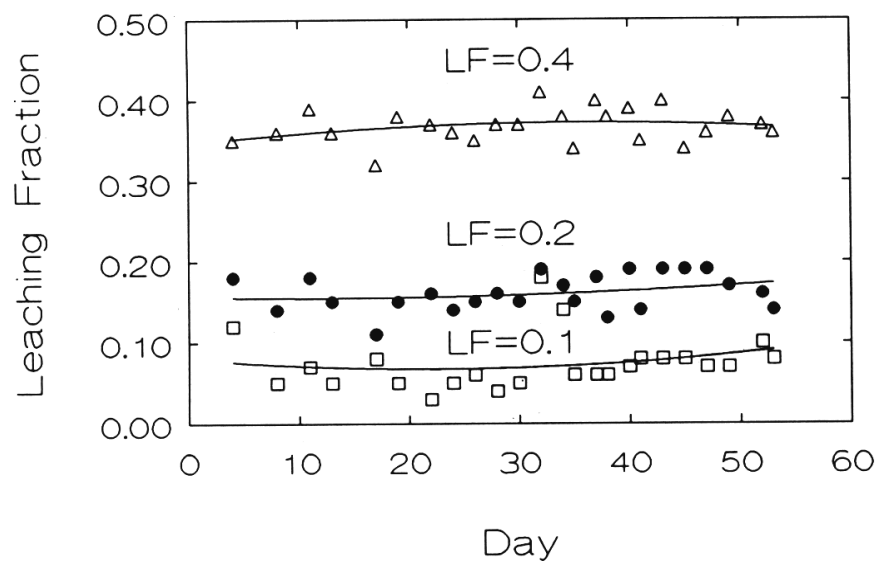

Fig. 2. Actual LF for intended LFs 0.1, 0.2, and 0.4. Each point represents a mean, $\mathrm{n}=5$. Second degree polynomial regressions $(\mathrm{n}=120)$ are $\mathrm{LF}=0.00000149 \times \mathrm{day}^{2}-0.000013 \times$ day + $0.07, \mathrm{r}^{2}=0.127$ for $\mathrm{LF}=0.1 ; \mathrm{LF}=0.000001 \times \mathrm{day}^{2}+0.000055$ $\times$ day $+0.153, r^{2}=0.219$ for $L F=0.2 ; L F=-0.00000430$ $\times \mathrm{day}^{2}+0.000622 \times \mathrm{day}+0.351, \mathrm{r}^{2}=0.224$ for $\mathrm{LF}=0.4$.

Table 2. Geranium height and leaf area at harvest.=

\begin{tabular}{ccc}
\hline $\begin{array}{c}\text { Leaching } \\
\text { fraction }\end{array}$ & $\begin{array}{c}\mathrm{Ht} \\
(\mathrm{cm})\end{array}$ & $\begin{array}{c}\text { Leaf area } \\
\left(\mathrm{cm}^{2}\right)\end{array}$ \\
\hline 0.0 & $18.4 \pm 1.2$ & $2480 \pm 157$ \\
0.1 & $15.8 \pm 0.8$ & $2690 \pm 281$ \\
0.2 & $16.8 \pm 0.2$ & $3700 \pm 66$ \\
0.4 & $17.6 \pm 0.5$ & $3920_{* * *}^{ \pm 280}$ \\
& $\mathrm{NS}$ & \\
\hline
\end{tabular}

${ }^{2}$ Data represent mean $\pm \mathrm{SE}, \mathrm{n}=5$.

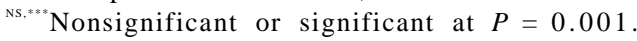

due to insufficient leaching. There was no significant difference in the dry mass partitioning among leaves, stems, and inflorescences among the LF treatments. Shoot dry mass was partitioned as follows: $50 \%$ in leaves, $23 \%$ in stems, and $27 \%$ in inflorescences.

Daily ET more than doubled during cropping (Fig. 3), which was different than for poinsettia where the ET remained more uniform. Seasonal changes probably accounted for these contrasting patterns. For spring-grown geraniums, ET increased with time due to increasing plant size and increasingly brighter and warmer weather. For fall-grown poinsettia, ET remained more constant because increased plant size was probably counterbalanced by less sunlight and cooler weather.

The pot mass after irrigation (M,) increased with time for all treatments (Fig. 4), unlike in the previous study (Ku and Hershey, 1991) where $M_{a}$ decreased over time for 0 LF plants. This
Table 3. Geranium leaf, flower, stem, and shoot fresh and dry masses with leaching fractions of 0 to 0.4 .'

\begin{tabular}{|c|c|c|c|c|c|}
\hline $\begin{array}{c}\text { Leaching } \\
\text { fraction }\end{array}$ & & Leaf & Flower & Stem & Total \\
\hline \multicolumn{6}{|c|}{ Fresh mass ( $g$ ) } \\
\hline 0.0 & 113 & \pm 8.7 & $61.2 \pm 3.3$ & $56.0 \pm 4.0$ & $230 \pm 16$ \\
\hline 0.1 & 118 & \pm 12 & $62.7 \pm 4.5$ & $58.4 \pm 7.2$ & $239 \pm 23$ \\
\hline 0.2 & 164 & \pm 1.5 & $67.8 \pm 7.8$ & $82.2 \pm 2.0$ & $314 \pm 6.8$ \\
\hline 0.4 & 177 & $\underset{* * *}{ \pm} 15$ & $\begin{array}{c}80.5 \pm 3.4 \\
\text { NS }\end{array}$ & $88.8_{* *}^{ \pm} 8.4$ & $346 \underset{* *}{ \pm} 25$ \\
\hline \multicolumn{6}{|c|}{ Dry mass ( $g$ ) } \\
\hline 0.0 & 11.6 & $5 \pm 0.5$ & $6.9 \pm 0.3$ & $5.5 \pm 0.3$ & $24.0 \pm 1.1$ \\
\hline 0.1 & 12.2 & $2 \pm 1.2$ & $7.2 \pm 0.5$ & $5.8 \pm 0.6$ & $25.1 \pm 2.3$ \\
\hline 0.2 & 16.3 & $3 \pm 0.4$ & $7.6 \pm 0.9$ & $7.9 \pm 0.2$ & $31.7 \pm 1.0$ \\
\hline 0.4 & 17.3 & $3 \underset{* *}{ \pm} 1.5$ & $\begin{array}{c}8.9 \pm 0.3 \\
\text { NS }\end{array}$ & $8.3_{* *}^{ \pm} 0.7$ & $34.5 \underset{\text { 我 }}{ \pm} 2.5$ \\
\hline
\end{tabular}

${ }^{2}$ Data represent mean $\pm \mathrm{SE}, \mathrm{n}=5$.

Ns, ${ }^{* *, * * *}$ Nonsignificant or significant at $P=0.01$ or 0.001 , respectively.

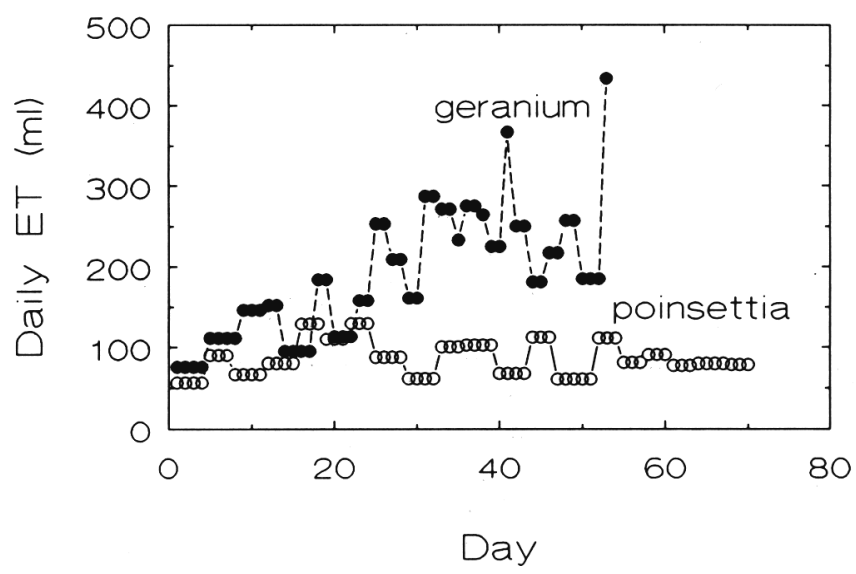

Fig. 3. Mean ET for LFs $0,0.1,0.2$, and 0.4. Each point represents a mean $\pm \operatorname{SE}(n=20)$. Data for geranium were from 18 Mar. to 9 May 1989, and data for poinsettia were from 10 Oct. to 16 Dec. 1988 (Ku and Hershey, 1991).

difference between the two studies was due to the revised method of irrigating $0 \mathrm{LF}$ plants in this study. The difference between the final and initial $\mathrm{M}_{\mathrm{a}}$ averaged 234, 234, 286, and $328 \mathrm{~g}$ for a $\mathrm{LF}$ of $0,0.1,0.2$, and 0.4 , respectively. This gain in $\mathrm{M}_{\mathrm{a}}$ was in agreement with the total shoot fresh masses at harvest (Table 3).

The leachate EC showed a linear and quadratic trend over sampling dates (Fig. 5). As with poinsettia, leachate EC ( $\mathrm{Ku}$ and Hershey, 1991) increased but eventually plateaued. This same pattern occurred with leachate nitrate level in container-grown chry- 


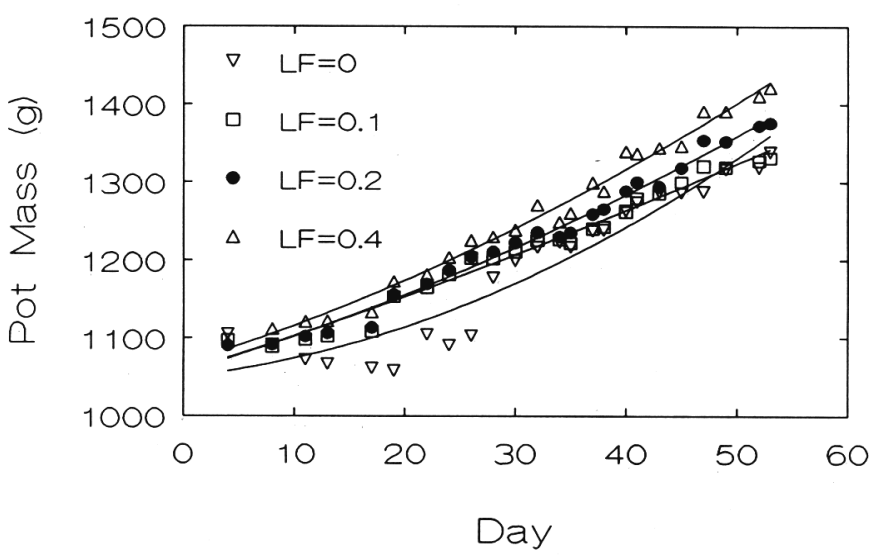

Fig. 4. Pot mass after fertigation $\left(\mathrm{M}_{\mathrm{a}}\right)$ for LFs $0,0.1,0.2$, and 0.4 . Each point represents a mean, $\mathrm{n}=5$. Second degree polynomial regressions $(\mathrm{n}=120)$ are $\mathrm{M}_{\mathrm{a}}=0.00297 \times \mathrm{day}^{2}+2.21 \times$ day $+1045, r^{2}=0.935$ for $L F=0 ; M_{a}=-0.00496 \times \mathrm{day}^{2}+$ $2.80 \times$ day $+1071, \mathrm{r}^{2}=0.963$ for $\mathrm{LF}=0.1 ; \mathrm{M}_{\mathrm{a}}=-0.00105$ $\times \mathrm{day}^{2}+2.69 \times$ day $+1073, \mathrm{r}^{2}=0.988$ for $\mathrm{LF}=0.2 ; \mathrm{M}_{\mathrm{a}}=$ $0.00000151 \times \mathrm{day}^{2}+2.86 \times$ day $+1086, \mathrm{r}^{2}=0.934$ for $\mathrm{LF}=$ 0.4 .

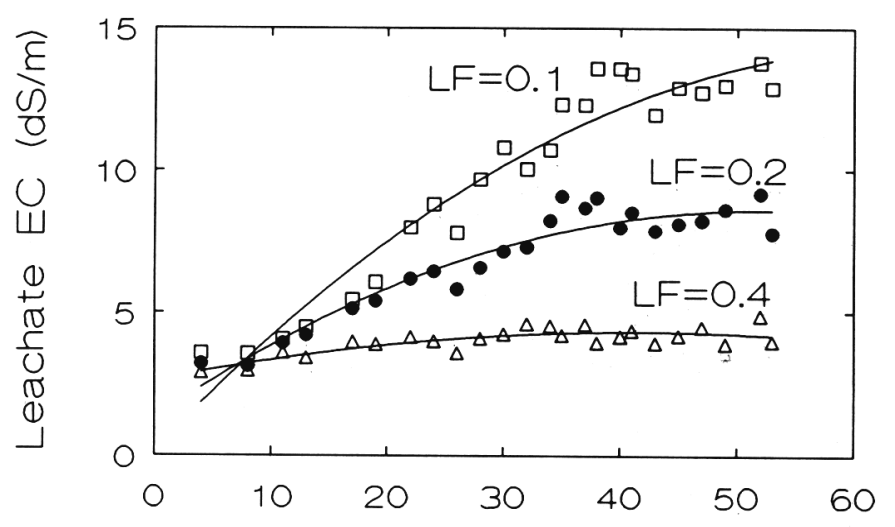

Day

Fig. 5. Leachate EC for LFs $0.1,0.2$, and 0.4. Each point represents a mean, $\mathrm{n}=5$. Second degree polynomial regressions $(\mathrm{n}=120)$ are EC $=-0.00095 \times \mathrm{day}^{2}+0.209 \times \mathrm{day}+1.77, \mathrm{r}^{2}=0.954$ for $\mathrm{LF}=0.1 ; \mathrm{EC}=-0.00868 \times \mathrm{day}^{2}+0.129 \times$ day +2.37 , $\mathrm{r}^{2}=0.948$ for $\mathrm{LF}=0.2 ; E C=-0.00020 \times \mathrm{day}^{2}+0.0331 \mathrm{x}$ day $+3.00, r^{2}=0.699$ for $L F=0.4$.

santhemum (Hershey and Paul, 1982). Leachate EC was highest at a LF of 0.1. Leachate EC for plants with $0.4 \mathrm{LF}$ plateaued at a much earlier date than that for plants with 0.1 or $0.2 \mathrm{LF}$.

Leachate $\mathrm{pH}$ decreased slightly over time (Fig. 6) probably -because of the relatively low irrigation water alkalinity and the ammonium in the fertigation solution. Ammonium could cause a $\mathrm{pH}$ decrease via nitrification or excess cation uptake by roots (Hershey, 1991). Plants with 0.1 LF frequently had a lower leachate $\mathrm{pH}$ than plants with a 0.2 or $0.4 \mathrm{LF}$. The leachate $\mathrm{pH}$ for all LF treatments at termination was -0.5 unit lower than the initial leachate $\mathrm{pH}$ of 5.5 .

The medium $\mathrm{EC}_{\mathrm{e}}$ varied among the upper, middle, and lower thirds of the pot (Fig. 7). Generally, the upper third of the medium had a higher EC, than the lower two-thirds. This result differed from those for poinsettia where EC, was higher in the lower third of the medium (Ku and Hershey, 1991). The difference may have been caused by different patterns of root dis-

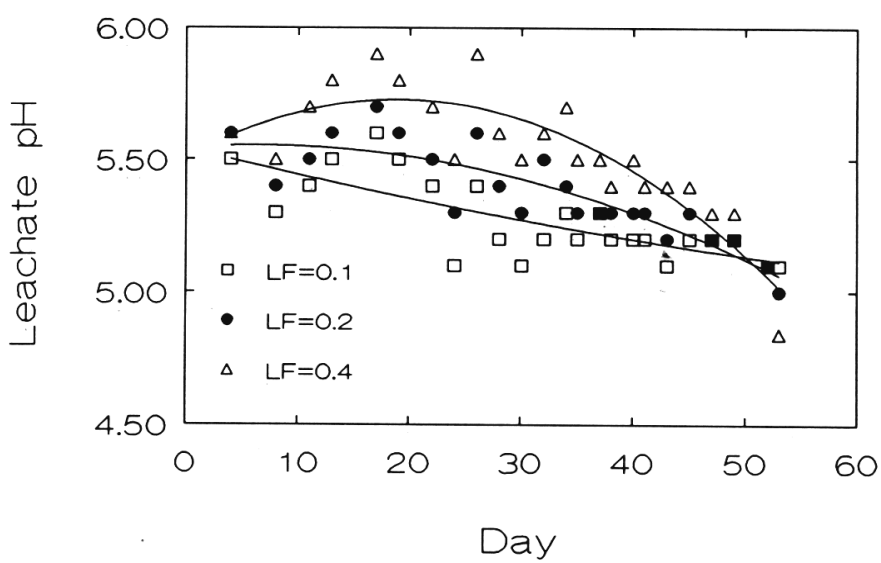

Fig. 6. Leachate $\mathrm{pH}$ for $\mathrm{LF}$ treatments 0.1, 0.2, and 0.4. Each point represents a mean, $\mathrm{n}=5$. Second degree polynomial regressions $(\mathrm{n}=120)$ are $\mathrm{pH}=0.000024 \times \mathrm{day}^{2}-0.0062 \times \mathrm{day}+5.54$, $\mathrm{r}^{2}=0.695$ for $\mathrm{LF}=0.1 ; \mathrm{pH}=-0.000014 \times \mathrm{day}^{2}-0.00270$ $\times$ day $+5.60, r^{2}=0.746$ for $L F=0.2 ; p H=-0.000091 x$ $\mathrm{d} \mathrm{a}^{2}+0.0055 \times \mathrm{day}+5.63, \mathrm{r}^{2}=0.805$ for $\mathrm{LF}=0.4$.

tribution between the two species, resulting in differential nutrient absorption in the three zones of the pot. However, root distribution was not examined., Alternatively, higher ET during geranium cropping (Fig. 3) could have caused upward migration of salts due to greater evaporation from the medium surface. With a 0 or $0.1 \mathrm{LF}$, the $\mathrm{EC}_{\mathrm{e}}$ was lower in the middle third than in the upper or lower thirds of the medium (Fig. 7). This pattern is consistent with flushing of salts into the bottom of the pot during irrigation and upward movement of salts due to evaporation from the medium surface. With a 0.2 or $0.4 \mathrm{LF}$, the EC, was about the same in the middle and lower thirds of the medium and highest in the upper third. The higher LFs caused much of the concentrated soil solution to be leached from the bottom two-thirds of the pot. The higher EC, in the upper layer is consistent with upward migration of salts due to evaporation from the medium surface.

Unlike EC, the medium $\mathrm{pH}_{\mathrm{e}}$ showed no correlation with LF (Fig. 7). Medium $\mathrm{pH}_{\mathrm{e}}$ differences were small, generally only a few tenths of a unit. Medium $\mathrm{pH}_{\mathrm{e}}$ was consistently lower in the upper third of the medium than in the lower two-thirds as also was the case for poinsettia ( $\mathrm{Ku}$ and Hershey, 1991).

Geraniums in this study were irrigated when the container medium was drier than it was in the study with poinsettia (Fig. 8 ). On average, geraniums were irrigated when at $51 \%$ of container capacity, while poinsettias were irrigated when at $64 \%$ of container capacity. Thus, the geraniums might have experienced greater salinity stress than poinsettias due to concentration of the soil solution between irrigations.

Hartmann et al. (1988) found geranium yields of $90 \%, 75 \%$, and $50 \%$ of maximum were associated with medium EC, values of $1.5,2.5$, and $5 \mathrm{dS} \cdot \mathrm{m}^{-1}$ at $25 \mathrm{C}$, respectively. The corresponding EC, values for poinsettia were $2.5,6.5$, and $12 \mathrm{dS} \cdot \mathrm{m}^{-1}$, respectively. In this study, a $26 \%$ decrease in shoot fresh mass was associated with an $\mathrm{EC}_{\mathrm{e}}$ at harvest of between 6 and $8 \mathrm{dS} \cdot \mathrm{m}^{-1}$ (Table 3). This does not agree with the predicted yield decline of $>50 \%$, suggesting that this geranium cultivar under our experimental conditions had greater salinity tolerance than predicted. This probably occurred because a gradual increase in rootzone EC during container crop production (Fig. 5) is less stressful than continuous irrigation with a high EC solution, as typically done in salinity tolerance studies. 
ZIA LFO L LFO.1 $\square$ LFO.2 LFO.4
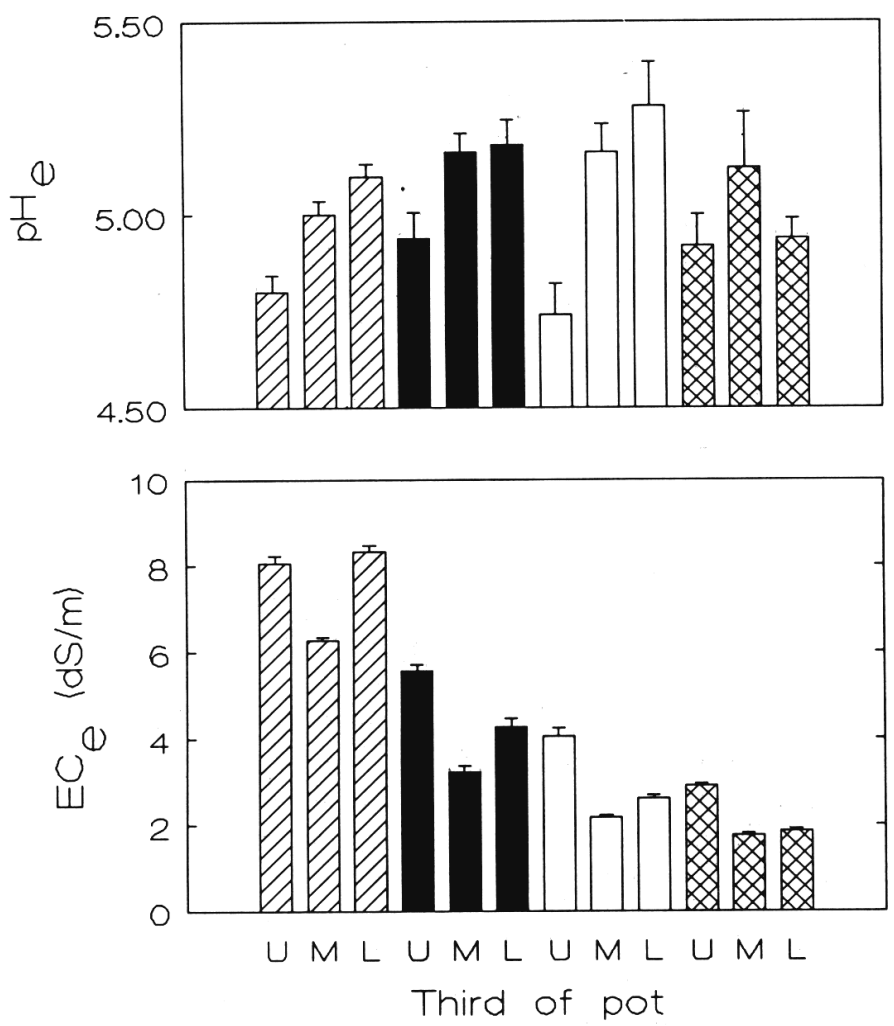

Fig. 7. Growing medium $\mathrm{EC}_{\mathrm{c}}$ and $\mathrm{pH}_{\mathrm{c}}$ at harvest for upper (U), middle (M), and lower (L) thirds of the pot. Each bar represents a mean, $\mathrm{n}=5$. Error bar is SE.

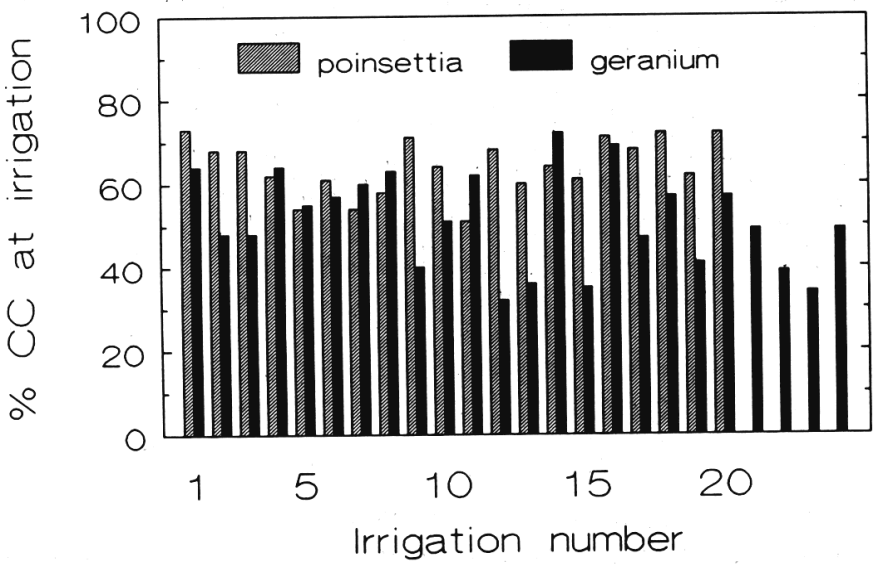

Fig. 8. Container medium water content expressed as a percentage of container capacity just before irrigation for glasshouse crops of spring-grown geranium and fall-grown poinsettia. Poinsettia data for crop described in $\mathrm{Ku}$ and Hershey (1991).

The LR equation, $\mathrm{LR}=\mathrm{EC}_{\mathrm{a}} / \mathrm{EC}_{1}$ (Ayers and Westcot, 1976) can be used to estimate the LF needed. Using the $\mathrm{EC}_{\mathrm{a}}$ of 2.1 $\mathrm{dS} \cdot \mathrm{m}^{-1}$ and steady state EC, values of 13,8 , and $4 \mathrm{dS} \cdot \mathrm{m}^{-1}$ gives a LR of $0.16,0.26$, and 0.53 , respectively. The LR equation was not the appropriate model since actual LFs were 0.076, 0.16 , and 0.37 , respectively (Table 1 ). This was a poorer agreement than obtained with poinsettia (Ku and Hershey, 1991). The overestimation of the LF by the LR equation was probably due to plant uptake of a substantial portion of the ions in the irrigation solution.
Ayers and Westcot (1976) also calculated the LR with a second equation: $\mathrm{LR}=\mathrm{EC}_{\mathrm{w}} /\left(2 \times \operatorname{maxEC}_{\mathrm{e}}\right)$, where $\mathrm{EC}_{\mathrm{w}}$ is the EC of the irrigation solution and $\operatorname{maxEC}_{\mathrm{e}}$ is the EC for $0 \%$ yield. The geranium yield data of Hartmann et al. (1988) give a maxEC of $9.4 \mathrm{dS} \cdot \mathrm{m}^{-1}$. The predicted $\mathrm{LR}$ for geranium is $0.11 \mathrm{using}$ the $\mathrm{EC}_{\mathrm{w}}$ of $2.1 \mathrm{dS} \cdot \mathrm{m}^{-1}$ in this study. This second equation appears to provide a better estimate for LR since geranium yield was significantly reduced at actual LFs of 0 and 0.076 compared to maximal growth at a LF of 0.16 or 0.37 .

Unlike poinsettia, yield of container-grown geranium declined as the LF decreased from 0.4 to 0 , possibly reflecting the lower salinity tolerance of geranium. Another important factor may be the time of year. Poinsettias are grown in fall when ET is relatively low, while geraniums are grown in spring when ET is usually higher. Also, media for geraniums are traditionally allowed to get drier between irrigations to reduce crop vigor, while media for poinsettia are not allowed to dry as much between irrigations. This difference existed here since the water content of the medium, just before irrigation, averaged $51 \%$ of container capacity for geranium but $64 \%$ for poinsettia (Fig. 8). Although the LFs were the same for the geraniums and poinsettias, the LIs were much higher for geraniums than for poinsettias. Thus, even when grown with higher LIs than poinsettia, geranium was less salinity tolerant.

The top dry mass for geraniums with LFs of 0 and 0.1 was $26 \%$ less than plants with LFs of 0.2 and 0.4 . The medium EC, of plants that received 0 and 0.1 LFs averaged 7.3 and 4.3 $\mathrm{dS} \cdot \mathrm{m}^{-1}$, respectively. These values were considerably higher than those for 0.2 and $0.4 \mathrm{LF}$ plants that had medium $\mathrm{EC}_{\mathrm{e}} \mathrm{s}$ of 3 and $2.2 \mathrm{dS} \cdot \mathrm{m}^{-1}$, respectively. However, plant appearance was not adversely affected. Plants that received a LF of 0 were visually similar to plants with a $0.1,0.2$, or 0.4 LF. Thus, under the conditions of this study, reducing the LF with geranium seemed a desirable strategy to reduce fertilizer leaching at the cost of slightly smaller plants. Although not examined here, reduction of the fertigation $\mathrm{N}$ concentration along with the LF might be an effective strategy to further reduce $\mathrm{N}$ leaching while avoiding salinity injury.

\section{Literature Cited}

Ayers, R.S. and D.W. Westcot. 1976. Water quality for agriculture. Irrigation and drainage paper 29. Food and Agr. Organization of the United Nations, Rome.

Biernbaum, J. and W. Fonteno. 1989. Minimize groundwater contamination. Greenhouse Grower 7(2):90-92, 94-95.

Bunt, A.C. 1988. Media and mixes for container-grown crops. UnWin Hyman, Boston.

Hartmann. H.T., A.M. Kofranek, V.E. Rubatzky, and W.J. Flocker. 1988. Plant science: Growth, development, and utilization of cultivated plants. Prentice Hall, Englewood Cliffs, N.J.

Hershey, D.R. 1989; Improved equipment for vacuum extraction of saturated growing media. HortScience 24:155.

Hershey, D.R. 1991. Acidity and basicity of fertilizers. J. Chem. Educ. 68:642.

Hershey, D.R. and J.L Paul. 1982. Leaching-losses of nitrogen from pot chrysanthemums with controlled-release or liquid fertilization. Scientia Hort. 17:145-152.

Ku, C.S.M. and D.R. Hershey. 1991. Leachate electrical conductivity and growth of potted poinsettia with leaching fractions of 0 to 0.4. J. Amer. Soc. Hort. Sci. 116:802-806.

Yelanich, M.V. and J.A. Biernbaum. 1990. Effect of fertilizer concentration and method of application on media nutrient content, nitrogen runoff and growth of Euphorbia pulcherrima 'V-14 Glory'. Acta Hort. 272:185-189. 